\title{
Innovation, Diffusion of New Technology and Productivity Growth: Evidence from African Agriculture
}

\author{
Kalu Ukpai Ifegwu \\ Department of Economics and Business Studies, Redeemer's University, Ede, Nigeria \\ Email address: \\ pstkay@yahoo.com
}

\section{To cite this article:}

Kalu Ukpai Ifegwu. Innovation, Diffusion of New Technology and Productivity Growth: Evidence from African Agriculture. International Journal of Agricultural Economics. Vol. 2, No. 1, 2017, pp. 9-14. doi: 10.11648/j.ijae.20170201.12

Received: August 29, 2016; Accepted: January 17, 2017; Published: February 21, 2017

\begin{abstract}
The paper studies the impacts of innovation and diffusion of new technology on productivity growth in African agriculture. Using FAO panel data, four output distance functions with linear programming method were calculated and the values used to obtain TFP growth estimates. The estimated TFP growth was decomposed into two distinct components associated with innovation and technology diffusion. The empirical results showed that TFP growth averaged $2.7 \%$ per year over the period studied. However, this performance masks the negative TFP growths (-1\% to $-2.8 \%)$ in the Sudan Sahelian, Eastern and Gulf of Guinea agro-ecological zones, respectively. This may be due to differences in the state of technology, the scale of production or efficiency. In terms of innovation and technology diffusion, a positive impact of innovation on TFP growth was observed only in two agro-ecological zones at $12.6 \%$ and $1.1 \%$ respectively. Whereas, the impact of diffusion of new technology was positive in all five agro-ecological zones at $2.5 \%, 2.4 \%, 2.3 \%, 2.1 \%$ and $0.2 \%$ in descending order of magnitude. Overall, the empirical results suggest that both innovation and technology diffusion have impacts on productivity growth, but the impact of technology diffusion is greater than the impact of innovation on agricultural productivity growth in the agro-ecological zones of Africa during 1986-2009.
\end{abstract}

Keywords: Innovation, Diffusion, Productivity Growth, Agriculture, Africa

\section{Introduction}

Innovation, when defined solely in technological terms refers to the development, imitation or adaptation, and the subsequent adoption of technologies. Innovation can also be broadly defined as the application of all types of knowledge; whether codified (explicit), tacit, scientific, technological, traditional, local, indigenous, theoretical or practical to bring new and or improved products, processes and services into social and economic use. It is considered an interactive, evolutionary or cumulative process that is embedded in an economic, organizational and institutional context [1]. At the same time, when new technologies are diffused and widely adopted, economy-wide productivity growth is generated [2]. In agriculture as in other sectors, innovation is the main driver of productivity growth. According to [3] agricultural innovations and diffusion of new technologies have been important factors in Africa's quest for food security. For example, the release of New Rice for Africa (NERICA) quadrupled rice yields in many African countries, and improved maize varieties have increased yields from less than one metric ton to more than four tons per hectare. Returns on new cotton varieties released in Senegal have been 34-37 percent. Investments in cocoa research in Nigeria led to the introduction of hybrid seed and effective control of the pests' capsid (an insect) and black pod (a fungus), producing annual returns of more than 40 percent. These technical breakthroughs required adaptation to the local level. They also required changes in organization and management, as well as in policies and institutions such as markets. Nevertheless, in some cases more needs to be done to help farmers make productive use of technical innovations. For example, the adoption of NERICA (a variety of rice) is still low. Many African farmers lack knowledge about the potential of this new rice variety or are discouraged by the additional labour it requires. Farmer adoption could be increased through innovative extension mechanisms to educate farmers and provision of affordable credit to allow farmers to hire labour. In Kenya, the average bunch weight of bananas increased from 15-30 kilograms $(\mathrm{kg})$ to more than $40 \mathrm{~kg}$; a combination of factors led to this improvement. The 
technical aspects of tissue culture and banana-ripening boxes played a part; just as important, however, were the provision of market information and channels to producers [3]. Previous studies have identified a key role of national research and development (R\&D) capacities in raising agricultural productivity in developing countries [4], [5], although agricultural $R \& D$ capacity in Africa has remained low by international norms [6-8]. Nevertheless, countries whose R\&D data are patchy or low, may modestly be improving their production practices over time, not through $\mathrm{R} \& \mathrm{D}$, but rather by innovative and adoptive activities that determine productivity growth. For these countries, most improvements are likely to be incremental and not paradigmatic. Incremental innovative activities not captured in formal R\&D can be accounted for by decomposing total factor productivity (TFP) growth into two components viz-aviz technical change and efficiency change. Improvement in the technical change component is considered to be evidence of innovation, while improvement in efficiency-change component is considered to be an evidence of diffusion of new technology [8]. TFP growth estimates and its components allow a much nuanced analysis of the impact of innovation on productivity growth. The main objective of the paper was to account for the impacts of innovation and diffusion of new technology on productivity growth in African agriculture. This was pursued by calculating four output distance functions with linear programming method, and using the values to obtain Malmquist TFP estimates. The estimated TFP growth was decomposed into its components associated with innovation and diffusion of new technology. The decomposition of total factor productivity is important as it provides a useful statistic to indicate how economic welfare in general and agricultural development in particular is being advanced through productivity gains in agriculture. By measuring changes in agricultural total factor productivity indices and most importantly being able to account for the impacts of innovation and diffusion of new technology on productivity growth, a substantial contribution would have been made towards understanding the mechanism at work in influencing agricultural productivity growth in Africa. Innovation and technology diffusion constitute the two separate components of total factor productivity that may be of importance to developing countries from the point of view of technology policy. The issue of factor productivity still remains significant in the agricultural sector of most African countries. The specific objectives of this paper were two folds: (i) to measure changes in TFP growth across the agroecological zones of Africa (ii) to account for the impact of innovation and diffusion of new technology on TFP growth across the agro-ecological zones. To guide research, the following hypotheses were stated (i) there are no changes in TFP growth across the agro-ecological zones (ii) innovation and diffusion of new technology do not impact TFP growth in the various agro-ecological zones. The rest of the paper is organized as follows: The next section presents the materials and methods. The empirical results are discussed in the third section. Finally, section 4 concludes the paper.

\section{Materials and Methods}

\subsection{Data and Variables}

The paper used FAO panel data to measure agricultural total factor productivity (TFP) growth changes in 26 African countries, sub-divided into five agro-ecological zones, namely, Northern, Sudan Sahelian, Eastern, Gulf of Guinea and Southern agro-ecological zones for the period 1986-2009. The panel data covered output and conventional agricultural inputs (land, labour, fertilizer, tractors and livestock). These sets of data were used to construct a piece-wise frontier over the data points. The use of panel data on zones over time enables an examination of the disaggregated forces underlying growth performance at the agro-ecological level, while controlling for unobserved heterogeneity in the sources of productivity growth. Table 1 presents the variable definitions and measurement.

\subsection{Method of Estimation}

To compute the Malmquist TFP index changes, four output distance functions with linear programming method were calculated and the values used to measure Malmquist TFP growth. The TFP growth was decomposed into its components associated with technical change and efficiency change. Technology in any given period is represented as an output distance function. The Malmquist productivity index introduced by [9] is based on the construction of a production frontier representing technology and employs the corresponding distance functions in order to measure productivity. From microeconomic theory, the production frontier identifies the maximum output that can be produced from given inputs and technology. A shift (which also results in a change in the maximum possible TFP) in the production frontier over time is referred to as technical change (TC). Technical efficiency (TE) is defined as a ratio of actual production to production on the frontier. That is, any production not on the production frontier is inefficient production.

An output distance function can be defined for a time ${ }^{t}$ as:

$$
\left.D_{0}^{t}\left(x^{t}, y^{t}\right)=\max \left\{\theta:\left(x^{t}, \theta y^{t}\right) \in S^{t}\right\}\right)^{-1}
$$

This shows by how much output(s) ${ }^{y}$ can be increased given a quantity of input(s) ${ }^{x}$, such that $x$ and $\theta y$ remain in the production set. The reference technology $S^{t}$ consists of observations of all decision- making units in time period $t$. To construct the Malmquist index, it is necessary to define distance functions with respect to two different time periods $t$ and $t+1$ as:

$$
\begin{aligned}
D_{0}^{t}\left(x^{t+1}, y^{t+1}\right) & =\left(\max \left\{\theta:\left(x^{t+1}, \theta y^{t+1}\right) \in S^{t}\right\}\right)^{-1} \\
D_{0}^{t}\left(x^{t}, y^{t}\right) & =\left(\max \left\{\theta:\left(x^{t}, \theta y^{t}\right) \in S^{t}\right\}\right)^{-1}
\end{aligned}
$$


The distance function specified by the first equation measures the maximum proportional change in output required to make $\left(x^{t+1}, y^{t+1}\right)$ feasible in relation to the technology used in period $t$. Similarly, the distance function specified by the second equation measures the maximal proportional change in output required to make $\left(x^{t}, y^{t}\right)$ feasible in relation to the technology set $S^{t+1}$ used in period $t+1$. [10] offer a decomposition of the rate of productivity change into two separate components measuring the rate of technical change and change in technical efficiency as two distinct components of productivity change. Technical difference between time $t$ and $t+1$ is measured as:

$$
T_{0}^{t+1}\left(y^{t+1}, x^{t+1}, y^{t}, x^{t}\right)=\left[\frac{D_{0}^{t}\left(x^{t+1}, y^{t+1}\right)}{D_{0}^{t+1}\left(x^{t}, y^{t}\right)} \times\left(\frac{D_{0}^{t}\left(x^{t}, y^{t}\right)}{D_{0}^{t+1}\left(x^{t+1}, y^{t+1}\right)}\right)\right]^{1 / 2}
$$

where, the numerator is the distance function equation, measured for $x^{t+1}$. Efficiency difference between period $t$ and $t+1$ is measured as:

$$
E_{0}^{t+1}\left(y^{t+1}, x^{t+1}, y^{t}, x^{t}\right)=\frac{D_{0}^{t+1}\left(x^{t+1}, y^{t+1}\right)}{D_{0}^{t}\left(x^{t}, y^{t}\right)}
$$

The Malmquist productivity index is the product of the efficiency index and the technical index:

$$
M_{0}^{t+1}=E_{0}^{t+1}+T_{0}^{t+1}
$$

Following [10] the Malmquist productivity index was later integrated in the Data Envelopment Analysis (DEA), using constant returns to scale technology for a bench mark. The DEA method is a non-parametric approach in which the envelopment of decision-making units (DMU) can be estimated through linear programming methods to identify the 'best practice' for each DMU. The efficient units are located in the frontier and the inefficient ones are enveloped by it. Four linear programmes (LPS) must be solved for each DMU to obtain the distances defined in equations (2 and 3 ) and they are:

$$
\begin{gathered}
{\left[d_{0}^{t}\left(x_{i, t,} y_{i, t}\right)\right]^{-1}=\max \phi, \lambda \varphi} \\
\text { St }-\varphi y_{i, t}+Y_{t} \lambda \geq 0, \\
x_{i, t}-X_{t} \lambda \geq 0 \\
\lambda \geq 0, \\
\text { st }-\varphi y_{i, t+1}+Y_{t+1} \lambda \geq 0, \\
\left.d_{0}^{t+1}\left(x_{i, t+1}, y_{i, t+1}\right)\right]^{-1}=\max \phi, \lambda \varphi \\
x_{i, t+1}-X_{t+1} \lambda \geq 0, \\
\lambda \geq 0, . \\
{\left[d_{0}^{t}\left(x_{i, t+1}, y_{i, t+1}\right)\right]^{-1}=\max \phi, \lambda \varphi,} \\
\text { st } \left.\left.-\varphi y_{i, t}+Y_{t+1} \lambda \geq 0, \quad y_{i, t+1}\right)\right]^{-1}=\max \phi, \lambda \varphi, \\
x_{i, t}-X_{t+1} \lambda \geq 0, \\
x_{i, t+1}-X_{t} \lambda \geq 0, \\
\lambda \geq 0,
\end{gathered}
$$

Where $\lambda$ are intensity variables which form the convex combinations of observed inputs and output, thereby forming the piece-wise linear best-practice reference technology. The intensity variables provide the (variable) weights given to each activity or observation to which observed points are compared.

Table 1. Variable Definition and Measurements.

\begin{tabular}{lll}
\hline Variable & Units & Definitions \\
\hline Output & Million USD & Quantity of agricultural production(1999-2001 price) \\
Land & 1,000 hectares & Sum of arable land, permanent crops and permanent pastures. \\
Labour & 1,000 persons & Number of persons who are economically actively engaged in agriculture \\
Tractor & Pieces & Total number of agricultural tractors in use \\
Fertilizer & Metric tons & Quantity of fertilizer plant nutrient consumed (N plus P2O5 plus K2O) \\
Livestock & 1,000 heads & Weighted average of the number of animals on farm (weights are: camels 1.1; buffalo, horses and mules 1.0; cattle and \\
\hline
\end{tabular}

\section{Results and Discussion}

\subsection{Changes in TFP Growth}

The changes in total factor productivity (TFP) were measured from the Malmquist index explained by (Eqn 2) and (Eqn 3) and following (Eqn 7-10), four output distance functions which explain by how much output quantities can be proportionally expended without altering the input quantities used, were estimated by linear programming methods. The values of the four distance functions were used to compute the Malmquist TFP index changes from period $t$ to period $t+1$, based on the constant-returns-to-scale technology. The value of TFP change 
greater than one reveals productivity improvement, and values less than one indicates regress in productivity. The results are presented in Table 2. The Malmquist index of productivity change showed a wide variability of TFP growth across the agro-ecological zones over the period 1986-2009. The Northern agro-ecological zone recorded an impressive improvement in productivity (TFP index was $15.4 \%$ ). The Southern agroecological zone also recorded productivity improvement with a TFP index of $3.5 \%$. However, a regress in productivity was observed in three agro-ecological zones. The highest productivity regress was recorded by the Eastern agro-ecological zone (TFP index $-2.8 \%$ ), followed by the Sudan Sahelian (TFP index $-1.8 \%$ ) and the Gulf of Guinea TFP index -1\%). This result agrees with [11] who observed a wide variability of TFP growth across Indian agriculture mainly due to differences in the state of technology or efficiency.

Table 2. Annual Means of Changes in Total Factor Productivity (TFP).

\begin{tabular}{llllll}
\hline Year & Northern & Sahelian & Eastern & Guinea & Southern \\
\hline 1986 & 1.000 & 1.000 & 1.000 & 1.000 & 1.000 \\
1987 & 2.746 & 1.277 & 2.652 & 2.354 & 2.863 \\
1988 & 1.457 & 1.231 & 1.674 & 1.283 & 1.315 \\
1989 & 1.227 & 1.188 & 1.396 & 1.216 & 1.288 \\
1990 & 0.828 & 0.865 & 1.186 & 0.025 & 0.112 \\
1991 & 0.318 & 2.371 & 1.221 & 2.776 & 2.977 \\
1992 & 1.918 & 1.180 & 0.013 & 1.235 & 1.280 \\
1993 & 1.311 & 1.133 & 2.633 & 1.269 & 1.246 \\
1994 & 1.225 & 0.351 & 1.522 & 0.199 & 0.629 \\
1995 & 1.293 & 0.187 & 1.298 & 2.550 & 2.885 \\
1996 & 1.297 & 1.819 & 1.168 & 1.321 & 1.493 \\
1997 & 1.908 & 1.300 & 1.124 & 1.259 & 1.365 \\
1998 & 1.432 & 1.201 & 0.105 & 0.298 & 0.019 \\
1999 & 1.365 & 1.401 & 2.655 & 2.651 & 3.241 \\
2000 & 0.239 & 0.390 & 1.524 & 1.319 & 1.746 \\
2001 & 0.574 & 1.401 & 1.019 & 1.222 & 1.343 \\
2002 & 1.798 & 1.727 & 1.040 & 0.037 & 0.454 \\
2003 & 1.357 & 1.343 & 1.379 & 2.242 & 2.916 \\
2004 & 1.218 & 1.245 & 0.143 & 1.426 & 1.476 \\
2005 & 0.546 & 0.129 & 2.573 & 1.236 & 1.227 \\
2006 & 2.186 & 1.426 & 1.526 & 2.311 & 0.117 \\
2007 & 1.434 & 1.393 & 1.278 & 2.843 & 2.867 \\
2008 & 1.337 & 1.264 & 1.183 & 1.408 & 1.452 \\
2009 & 1.154 & 1.041 & 1.196 & 1.330 & 1.404 \\
Mean & 1.154 & 0.982 & 0.972 & 0.990 & 1.035 \\
\hline
\end{tabular}

Note: TFP change is calculated relative to a constant-returns-to-scale technology. Annual values are geometric means of individual country values and overall mean is the geometric mean over individual years.

\subsection{Impact of Innovation and Diffusion of New Technology on TFP Growth}

In order to account for the impact of innovation and the diffusion of new technology, the estimated TFP growth was decomposed into its distinct components; technical change and efficiency change. The technical change (innovation) component was obtained by applying (Eqn 4). Technical change has been the major driving force for increasing agricultural productivity and promoting agriculture development. The results are presented in Table 3. Recall that improvements in the impact of innovation on TFP growth are associated with technical change values greater than unity and regress or deterioration is associated with values less than unity. As shown in the Table 3, innovation has values greater than one, indicating improvements and hence positive impacts on TFP growth both in the Northern and Southern agro-ecological zones. In the Northern agroecological zone, technical change or innovation impacted TFP growth index by $12.6 \%$ and by $1.1 \%$ in the Southern agroecological zone respectively. These positive impacts on productivity improvements may most likely be the results of the application of technical inputs like hybrid seeds, fertilizer, irrigation etc. usually referred to as product innovation. Technical change was however, subject to regress in three out of the five agro-ecological zones, and hence negative impacts on TFP growth index. In the Eastern agro-ecological zone, innovation impacted TFP growth index negatively $(-4.9 \%)$, followed by the Gulf of Guinea (-3.1\%). The negative impact of innovation on TFP growth index was also negative $(-2 \%)$ in the Sudan Sahelian. These negative impacts may be due to the losses in year- wise estimates of technical change indices observed in 4 out of 24 years in both Eastern and Gulf of Guinea agro-ecological zones and 5 out of 24 years in the Sudan Sahelian respectively as shown in the Table 3 . Among the possible explanations for the heavy technical change losses over the years could be the fact that implementation of technical changes is resource-intensive and the laggards appeared to have struggled to keep up with technological advances in the agricultural sector over the period and therefore the negative impacts of innovation on TFP growth indices. In order to improve agricultural productivity, it is important for developing countries of Africa to tailor agricultural policies to those that favour the use of fewer resources relative to those that are resource-intensive.

Table 3. Annual Mean Values of Technical Change (Innovation).

\begin{tabular}{llllll}
\hline Year & Northern & Sahelian & Eastern & Guinea & Southern \\
\hline 1986 & 1.000 & 1.000 & 1.000 & 1.000 & 1.000 \\
1987 & 1.779 & 1.207 & 1.915 & 1.494 & 1.785 \\
1988 & 1.367 & 1.350 & 1.554 & 1.276 & 1.304 \\
1989 & 1.147 & 1.126 & 1.307 & 1.187 & 1.188 \\
1990 & 1.216 & 1.241 & 1.144 & 0.046 & 0.213 \\
1991 & 0.300 & 1.275 & 1.212 & 1.617 & 1.622 \\
1992 & 1.429 & 1.707 & 0.022 & 1.239 & 1.275 \\
1993 & 1.350 & 1.108 & 1.896 & 1.196 & 1.269 \\
1994 & 1.174 & 1.157 & 1.412 & 0.333 & 1.093 \\
1995 & 1.433 & 1.258 & 1.239 & 1.656 & 1.843 \\
1996 & 1.528 & 0.063 & 1.164 & 1.223 & 1.443 \\
1997 & 1.533 & 1.676 & 1.077 & 1.271 & 1.250 \\
1998 & 1.463 & 1.196 & 0.179 & 0.495 & 0.034 \\
1999 & 1.269 & 1.189 & 1.851 & 1.699 & 2.022 \\
2000 & 0.624 & 0.735 & 1.301 & 1.237 & 1.650 \\
2001 & 0.280 & 0.902 & 0.999 & 1.193 & 1.219 \\
2002 & 1.486 & 1.568 & 1.080 & 0.057 & 0.812 \\
2003 & 1.267 & 1.246 & 1.354 & 1.669 & 1.901 \\
2004 & 1.268 & 1.247 & 0.233 & 1.319 & 1.351 \\
2005 & 0.881 & 0.982 & 1.845 & 1.176 & 1.193 \\
2006 & 1.418 & 0.199 & 1.426 & 4.192 & 0.204 \\
2007 & 1.357 & 1.393 & 1.194 & 1.676 & 1.741 \\
2008 & 1.345 & 1.135 & 1.182 & 1.405 & 1.504 \\
2009 & 1.123 & 1.047 & 1.162 & 1.257 & 1.268 \\
Mean & 1.126 & 0.980 & 0.951 & 0.969 & 1.011 \\
\hline & & & & & \\
\hline
\end{tabular}

Note: Technical change is calculated relative to a constant-returns-to-scale technology. Annual values are geometric means of individual country values and overall mean is the geometric mean over individual years. 
Turning to the efficiency change (diffusion of new technology) component of total factor productivity growth which was obtained by applying (Eqn 5), calculated relative to the constant-returns-to-scale technology. The result presented in Table 4 indicate that efficiency improvement which is defined as the decrease in the distance between zones' realised output and potential output was observed in all the agro-ecological zones, indicating the impact of diffusion of technology on TFP growth. The impact of technology diffusion on TFP growth index was positive both in the Northern and Southern agro-ecological zones with improvements of $2.5 \%$ and $2.4 \%$ respectively. In the Sudan Sahelian agro-ecological zone, the impact of technology diffusion on TFP growth index was marginally positive at $0.2 \%$. While in the Eastern and the Gulf of Guinea agroecological zones, the impacts of technology diffusion on TFP growth indices were positive with medium improvements of $2.3 \%$ and $2.1 \%$ respectively. These could be the effects of better production practices over time e.g. proper timing, better farm management practices, and changes in cropping pattern, etc. The positive impact of diffusion of new technology in all the agro-ecological zones implies that the rate technology diffusion and/or changes in learning by doing activities are more important sources of productivity growth relative to technical change. Overall, the empirical results suggest that both innovation and technology diffusion have impacts on productivity growth, but the impact of technology diffusion is greater than the impact of innovation on agricultural total factor productivity growth in the agroecological zones of Africa during 1986-2009. Therefore, policies that result in efficiency change are likely to have more impact on the future prospects of the agricultural sector relative to policies that foster technical change. Consequently, policies to encourage learning by doing activities should be given much more attention in the quest to improve countries' productivity.

Table 4. Annual Mean Values of Technical Efficiency Change (Diffusion of Technology).

\begin{tabular}{llllll}
\hline Year & Northern & Sahelian & Eastern & Guinea & Southern \\
\hline 1986 & 1.000 & 1.000 & 1.000 & 1.000 & 1.000 \\
1987 & 1.543 & 1.058 & 1.385 & 1.576 & 1.604 \\
1988 & 1.066 & 0.912 & 1.077 & 1.005 & 1.009 \\
1989 & 1.070 & 1.055 & 1.068 & 1.025 & 1.085 \\
1990 & 0.680 & 1.036 & 1.037 & 0.548 & 0.528 \\
1991 & 1.060 & 0.678 & 1.007 & 1.717 & 1.836 \\
1992 & 1.342 & 1.389 & 0.616 & 0.997 & 1.004 \\
1993 & 0.871 & 1.065 & 1.389 & 1.061 & 0.982 \\
1994 & 1.044 & 0.979 & 1.078 & 0.597 & 0.575 \\
1995 & 0.902 & 0.279 & 1.048 & 1.540 & 1.565 \\
1996 & 0.849 & 2.970 & 1.003 & 1.080 & 1.035 \\
1997 & 1.245 & 1.086 & 1.043 & 0.991 & 1.091 \\
1998 & 0.979 & 1.087 & 0.587 & 0.602 & 0.552 \\
1999 & 1.076 & 1.010 & 1.435 & 1.560 & 1.603 \\
2000 & 0.383 & 0.531 & 1.172 & 1.066 & 1.058 \\
2001 & 2.053 & 1.553 & 1.020 & 1.024 & 1.102 \\
2002 & 1.210 & 1.101 & 0.962 & 0.653 & 0.560 \\
2003 & 1.072 & 1.078 & 1.018 & 1.343 & 1.534 \\
2004 & 0.961 & 0.999 & 0.613 & 1.081 & 1.093 \\
2005 & 0.620 & 0.132 & 1.394 & 1.051 & 1.028 \\
\hline
\end{tabular}

\begin{tabular}{llllll}
\hline Year & Northern & Sahelian & Eastern & Guinea & Southern \\
\hline 2006 & 1.542 & 7.165 & 1.070 & 0.551 & 0.572 \\
2007 & 1.057 & 1.000 & 1.070 & 1.696 & 1.647 \\
2008 & 0.994 & 1.113 & 1.000 & 1.002 & 0.965 \\
2009 & 1.027 & 0.994 & 1.029 & 1.059 & 1.107 \\
Mean & 1.025 & 1.002 & 1.023 & 1.021 & 1.024 \\
\hline
\end{tabular}

Note: Technical efficiency changes are calculated relative to a constantreturns-to-scale technology. Annual values are geometric means of individual country values and overall mean is the geometric mean over individual years.

\section{Conclusion}

The paper studies the impacts of innovation and diffusion of new technology on productivity growth at the level of agro-ecological zones of Africa. Using FAO panel data, four output distance functions with linear programming method were calculated and the values were used to compute the Malmquist TFP growth changes. The estimated TFP growth was decomposed into its components associated with technical change and efficiency change. The components of productivity growth were interpreted as follows: improvement in the technical change component was considered to be evidence of innovation, while improvement in efficiency-change component was considered to be an evidence of technology diffusion. This decomposition thus provided an alternative way of accounting for the impacts of innovation and technology diffusion of the informal activities not captured in R\&D on productivity growth. The empirical results showed that TFP growth indices in the Northern agroecological zone exhibited positively large improvement at $15.4 \%$. TFP growth recorded medium positive improvement at $3.5 \%$ in the Southern agro-ecological zone. Whereas, in the remaining three zones TFP growth improvement were negative at $-1.8 \%,-2.8 \%$ and $-1 \%$ in the Sudan Sahelian, Eastern and Gulf of Guinea agro ecological zones respectively. The negative productivity growth in three zones implies that output growth was contributed by input growth. These findings agree with [11] who observed variability in productivity growth across Indian agriculture and attributed it to differences in the state of technology and efficiency. In terms of the impact of innovation and technology diffusion on productivity growth, the impact of innovation on TFP growth was positive only in the Northern and Southern agroecological zones. In the other three zones, the impacts of innovation were negative as they failed to keep up with the innovations in the production process of the best-practice. This result is corroborated by [6] who suggested that technical regress may be attributed to falling public investment in agriculture and may have contributed negatively to productivity growth. Meanwhile the impacts of technology diffusion/ learning-by- doing were positive in all the five agro-ecological zones studied. The general conclusion that can be drawn is that both innovation and technology diffusion have impacts on productivity growth, but the impact of technology diffusion is greater than the impact of innovation on agricultural total factor productivity growth in the agro-ecological zones of Africa during 1986- 
2009. This suggests that policies that result in technical change are likely to have little impact on the future prospects of the agricultural sector relative to policies that foster the diffusion of technology. This could justify government support which helps to diffuse and adopt available technology.

\section{Acknowledgement}

An earlier version of this paper was selected for poster presentation at the $13^{\text {th }}$ GLOBELICS International conference held at Havana, Cuba on September $23^{\text {rd }}-25^{\text {th }}$, 2015. The author would like to thank Prof. J. O. Ajetomobi for his useful comments. The usual disclaimer holds.

\section{References}

[1] J. Fagerberg, and M. Srholec, "Knowledge, Capabilities and the Poverty Trap: The complex interplay between technological, social and geographical factors", in Meusburger, P., Glückler, J. and el Meskioui, M. (eds.), Knowledge and the Economy, Springer: 113-137, 2013.

[2] J. Perla, C. Tonetti, and M. E. Waugh: "Equilibrium Technology Diffusion, Trade, and Growth," Working Paper 20881, National Bureau of Economic Research, 2015.

[3] N. Beintema,, and G. Stads African Agricultural $R \& D$ in the New Millennium: Progress for Some, Challenges for Many. IFPRI Food Policy Report, Agricultural Science and Technology Indicators, International Food Policy Research
Institute, Washington, DC 2011.

[4] K. O. Fulgie and N. E. Rada Resources, Policies, and Agricultural Productivity in sub-Saharan Africa, ERR 145, U.S. Department of Agriculture, Economic Research Service, February, 2013.

[5] R. Evenson and K. Fuglie "Technological Capital: The Price of Admission to the Growth Club" in Journal of Productivity Analysis 33: 173-90, 2010.

[6] P. Rezek, R. Campbell, and K. Rogers "Assessing Total Factor Productivity Growth in Sub-Saharan African Agriculture" Journal of Agricultural Economics 62: 357-74, 2011.

[7] R. Paarlberg Starved for Science: How Biotechnology Is Being Kept Out of Africa. Cambridge, MA: Harvard University Press, 2008.

[8] A. Nin-Pratt, and B. Yu. "Agricultural Productivity and Policy Changes in Sub-Saharan Africa," in Agricultural Productivity: A Global and Regional Analysis, K. Fuglie, S. L. Wang, and V. E. Ball, eds. Oxfordshire, UK: CAB International 2012.

[9] D. Caves, L. Christensen and E. Diewert "The Economic Theory of Index Numbers and the Measurement of Input, Output, and Productivity" Econometrica. (50): 1393- 1414, 1982.

[10] R. Fare, S. Grosskopf, and C. A. K. Lovell Production frontiers Cambridge: Cambridge University Press, 1994.

[11] P. Singer and A. Singer "Decomposition of Technical Change and Productivity Growth in Indian agriculture using NonParametric Malmquist Index" Eurasian Journal of Business and Economics. 5 (9), 187-202, 2012. 